\title{
IDENTIDAD DE LA TEOLOGÍA LATINOAMERICANA Y LA TEOLOGÍA DE LA LIBERACIÓN
}

The identity of Latin American Theology and the Theology of Liberation

Jorge Costadoat *

RESUMEN: El objetivo de esta investigación es suministrar argumentos para identificar la Teología latinoamericana con la Teología de la liberación, y viceversa. Entre estos argumentos se debe considerar la conciencia de alcanzar la "mayoría de edad" de la Iglesia en América Latina en el postconcilio; la convicción de los teólogos de la liberación de estar elaborando una "nueva manera" de hacer teología; una toma de distancia del carácter ilustrado de la teología; y la posibilidad de reconocer en los acontecimientos regionales, particularmente en los pobres, un habla original de Dios. Este artículo pretende hacer una contribución al status quaestionis del método teológico.

PALABRAS CLAVE: Iglesia Latinoamericana. Método. Lugar teológico. Teólogo. Opción por los pobres.

ABSTRACT: The objective of this paper is to provide arguments to identify Latin American Theology with Liberation Theology, and vice versa. Among these arguments, one should consider the awareness of the Church in Latin America reaching its "age of maturity" in the post-conciliar period. Other arguments are the conviction of liberation theologians to be elaborating a "new way" of

* Pontificia Universidad Católica de Chile, Santiago do Chile. 
doing theology; a distance from the illustrated characteristic of theology; and, the possibility of recognizing in regional events, particularly in the poor, God's original speech. This article aims to contribute to the status quaestionis of the theological method.

KEYWORDS: Latin American Church. Method. Theological Place. Theologian. Option for the poor.

\section{Introducción}

A ños atrás debí elaborar una bibliografía de la cristología latinoameAricana (COSTADOAT, 2004, p. 18-61). Tuve dificultades para hacerlo. ¿Debía entenderse por "latinoamericana" solo la cristología de la liberación? No estuve en condiciones de resolver el problema teológico que esta pregunta me planteaba. ¿La bibliografía sería latinoamericana por el lugar de nacimiento del autor de un determinado libro o artículo? ¿Por el lugar de publicación de la revista u obra? Había autores europeos que habían hecho contribuciones escritas notables en cristología de la liberación, las cuales habían sido publicadas en América Latina y en Europa. Por otra parte, había también teólogos nacidos en el continente cuya teología no se distinguía para nada de la teología europea. Resolví el asunto del modo más fácil: incluí en la bibliografía todo lo que más o menos tenía que ver con Jesucristo y con América Latina. Pero quedó en suspenso la cuestión teológica señalada.

El propósito de la investigación que sigue a continuación ha sido contribuir a forjar un concepto que identifique la Teología latinoamericana con la Teología de la liberación. Mi conclusión -como espero probar en adelante- es que toda auténtica Teología latinoamericana, que pone énfasis en el latinoamericano como sujeto de una praxis histórica, eclesial y teológica, no puede sino ser una teología de la liberación; y, respectivamente, toda auténtica Teología de la liberación, que tiene por objeto la liberación de los latinoamericanos de las más diversas maneras de opresión, no ha podido sino tener en cuenta a estos como protagonistas sociales, culturales y religiosos de su historia. Estos dos aspectos de una misma teología, que puede llamarse Teología latinoamericana de la liberación o Teología de la liberación latinoamericana, sellan la diferencia con la teología europea de la que se ha dependido en América Latina por 500 años y que a veces, camufladamente, la "derecha" o la "izquierda" quieren hacérnoslas pasar como nuestra.

En una primera sección de este artículo, diré algo sobre la búsqueda de la adultez que el catolicismo latinoamericano practicó en los años sesenta. En una segunda sección, trataré de explicar qué ha de entenderse por "un nuevo modo" de hacer teología, expresión muy usada por los teólogos de 
la liberación para hablar de una característica de su teología. En una tercera sección, pondré en relación la Teología de la liberación con la modernidad ilustrada, haciendo ver la tensión fundamental que esta relación provoca entre distintas corrientes liberacionistas latinoamericanas. Por último, me gustaría contribuir a encontrar el status quaestionis metodológico de la Teología latinoamericana de la liberación.

\section{El camino a la adultez de la Iglesia latinoamericana}

El Concilio Vaticano ha llegado a adquirir una importancia enorme, y decisiva, para la Iglesia latinoamericana. Uno de los frutos latinoamericanos del Concilio fue la adultez con que la Iglesia de los años sesenta llevó a efecto, en su propio contexto histórico, el aggiornamento impulsado por Juan XXIII.

La recepción de Vaticano II en América Latina fue adulta en varios aspectos. La jerarquía eclesiástica tuvo el coraje -gracias el método que tomó de Gaudium et spes- de abrirse a los signos de su tiempo, de dejarse cuestionar por la palabra de Dios expresada en las voces de multitudes de obreros, de campesinos y de hacinados en las grandes ciudades, y de adaptar su modo de ser a la praxis que asumió para responder a lo que se demandaba de ella. Este formidable empeño de recepción local del Concilio, fue concomitante al nacimiento de una nueva versión de la Teología latinoamericana. La Teología latinoamericana ha podido significar dos cosas antes y después del Concilio. En palabras de Juan Noemi, "con anterioridad al Vaticano II predomina un ejercicio teológico para el cual el contexto espacial y temporal constituye una exterioridad, un accidente que no es considerado en sí mismo como determinante del teologizar" (NOEMI, 1998, p. 1). La teología de la Iglesia del continente antes del Vaticano II fue, en realidad, meramente europea, destinada a la formación de los seminaristas. En cambio, desde el momento que se dio entre nosotros una teología destinada a pensar los acontecimientos históricos en los cuales arraigaba la Iglesia, la Teología latinoamericana ha podido identificarse con la Teología de la liberación sin más ${ }^{1}$.

Este acceso al "uso de razón" de la Iglesia en América latina -valga aquí la analogía de los niños cuando comienzan a pensar por sí mismos (NO-

\footnotetext{
${ }^{1}$ Ha sido importante entre los teólogos de la liberación recordar que durante la Conquista se dio una primera "teología de la praxis" desarrollada por Las Casas y algún otro. Sin embargo, es exagerado sostener, a mi parecer, que esta pueda considerarse "el nacimiento de la teología de la liberación latino-americana" (Enrique Dussel, Teología de la liberación, Potrerillos editores, México, 1995, 38). Por entonces se estuvo lejos de pensar, por ejemplo, que el indio pudiera de algún modo ser "teólogo", es decir, sujeto de su propia praxis de liberación.
} 
EMI, 1998, p. 21)- se abrió espacio en tensión, y veces en conflicto, con una dependencia intelectual inveterada del continente y de la Iglesia latinoamericanos. En palabras de Gustavo Gutiérrez: "La teología de la liberación es una de las expresiones de la adultez que comienza a alcanzar la sociedad latinoamericana y la Iglesia presente en ella en las últimas décadas. Medellín tomó acta de esta edad mayor y ello contribuyó poderosamente a su significación y alcance históricos" (GUTIÉRREZ, 2013, p. 14)2. Es así que la convergencia en Medellín de la jerarquía eclesiástica y los teólogos de la naciente Teología de la liberación, debe considerarse un hito de una Iglesia en camino de su autoconciencia y de la autonomía que distingue a los mayores de edad obligados a responder ante nuevas circunstancias por sí mismos y ante sí mismos con creatividad. La recepción del Concilio en América Latina fue sin duda original (NOEMI, 1998, p. 13).

Más adelante veremos que la Teología de la liberación no fue tan creativa en cuanto a su método. Pero al aplicar la Iglesia un método inductivo para auscultar sus propios signos de los tiempos resultó una novedad mayor en la historia del cristianismo, a saber, haber concluido y haber proclamado que Dios opta por los pobres. Esta convicción y formulación teológicas propias de la Iglesia en América Latina sobrepasa con creces el cuidado que la Iglesia siempre ha tenido de los pobres. Esta opción, en una Iglesia que ha practicado una reflexión sobre su propia experiencia histórica, confrontada con una miseria injusta y antigua entre los oprimidos, equivale a incorporar a los pobres en el Credo. Para los católicos latinoamericanos -oficialmente representados- el valor teológico de los pobres ha llegado a constituir la prueba de fuego de la fidelidad al Evangelio. No digo que la opción de Dios por los pobres constituya un nuevo dato de la fe. Lo novedoso es que la opción por los pobres explicita el misterio de la cruz de Cristo. Los pobres, para la teología de la liberación, representan al crucificado en la historia y a través de ellos Cristo crucificado salva a los seres humanos sin exclusión (SOBRINO, 1991, p. 333). En este sentido, el aporte teológico de la Iglesia latinoamericana ha llegado a ser duradero e imprescindible también para otras iglesias.

Los años sucesivos a Medellín, no sin el apoyo de los pontífices, pero también con la oposición de obispos, de conferencias episcopales y de la Congregación para la Doctrina de la Fe, la Teología latinoamericana de la liberación se desarrolló de un modo inédito. En ella es posible distinguir diversas corrientes: unas admitieron un influjo mayor del marxismo y otras, como la Teología argentina del pueblo, ninguno (Cf. SCANNONE, 1982, p. 3-40); se desarrolló una Teología feminista y una Teología indígena. Estas tienen en común la opción por los pobres y darle suma importancia a la

\footnotetext{
${ }^{2}$ La cursiva es mía.
} 
praxis de liberación. Si en sus comienzos la Teología latinoamericana fue identificada por su pretensión liberadora socio-política, progresivamente ha sido reconocida, además, por hacer suya la cultura, la religiosidad y la condición de pueblos y sujetos emergentes (BEOZZO, HÜNERMANN, SCHICKENDANTZ, 2006).

En esta búsqueda de su propia identidad, la Teología de la liberación ha procurado insistentemente en distinguirse de la Teología europea. Jon Sobrino ha puesto la diferencia entre ambas en el plano del conocimiento teológico. Para el teólogo de la UCA del Salvador, toda teología se mueve por un interés. El interés de la Teología europea, según él, sería responder a los desafíos de la primera Ilustración. Esto es, "explicar la verdad de la fe y esclarecer su sentido oscurecido". "La pregunta a responder, en su caso, ha sido ¿cómo se puede creer hoy; qué sentido tiene la fe hoy, cuando parece que ha perdido su sentido?". La Teología de la liberación, en cambio, moviéndose en el registro de la segunda Ilustración, se ha interesado más en "liberar a la realidad de su miseria, pues es eso lo que ha oscurecido el significado de la fe". La Teología europea y la Teología de la liberación han partido de presupuestos diferentes. "La europea ha tenido como punto de arranque un depósito de verdades que ella ha de trasmitir, explicar, interpretar y hacer significativos". La de la liberación, en cambio, echa sus raíces epistemológicas en la praxis de liberación, en un seguimiento de Cristo que ha podido ser conflictivo y martirial. Para Sobrino, en síntesis, la Teología de la liberación supera a la Teología europea, pues "conocer la verdad es hacer la verdad, conocer a Jesús es seguir a Jesús". (SOBRINO, 1981, p. 35)

Esta necesidad de distinguirse la Teología latinoamericana de la romana en particular, también tuvo algunas expresiones pre-conciliares importantes de recordar. Según Marcos Mc Grath, redactor de Gaudium et spes y personaje clave en Medellín:

“Esta inmensa porción del cristianismo que es Latinoamérica ya no puede seguir en una fase de infantilismo intelectual, recibiendo hasta los últimos puntos y comas de su pensamiento, de otras tierras. Lo que es la doctrina, lo que es magisterio, los caminos seguros de teología que la Iglesia romana nos señala, todo ello será nuestra base. Sin embargo, es imprescindible que logremos nuestra propia expresión de estas verdades y estos valores frente a lo que nos rodea, aquí en donde la suerte de casi la mitad de los cristianos del mundo está en juego" (MC GRATH, 1961, p. 16-17)3.

En suma, la Iglesia en América Latina, de la mano de la Teología de liberación, esto es, de la Teología latinoamericana post-conciliar, pudo avanzar a partir de los años sesenta en superar el "infantilismo intelectual", señalado por Mc Grath, y contrarrestar la "debilidad orgánica"

\footnotetext{
${ }^{3}$ El destacado es mío.
} 
que Pablo VI había constatado en su catolicismo ${ }^{4}$. Al cumplirse cincuenta años del acontecimiento eclesial y teológico que fue Medellín, la Iglesia latinoamericana puede decir por primera vez en su historia que tiene una teología propia, que esta es reflexión sobre su propia experiencia de Dios (fides qua) antes que sobre la fe objetiva de la Iglesia (fides quae) y que el sujeto primordial de la misma es el pobre. Lo afirma Noemi en términos muy significativos: "Formal y muy sintéticamente el recurso a los pobres le permite a la teología de la liberación validarse como teología de la historia en la medida que ellos se postulan tanto sujeto de la historia como sujeto de la teología" (NOEMI, 1998, P. 33).

\section{Un "nuevo modo" de hacer teología ${ }^{5}$}

Sostener que la teología de la liberación era "un nuevo modo" de hacer teología, fue una expresión muy común en los inicios de su desarrollo (GUTIÉRREZ, 1982; BOFF, L., 1975; SOBRINO, 1992; SCANNONE, 1984; LÓPEZ, 1999; ALONSO, 1987; CODINA, 1987). Son numerosos autores que la usaron $y$, en los años sucesivos, ella ha continuado siendo una idea importante.

Un mirada atenta al uso de la expresión, sin embargo, deja la impresión de que no todos los teólogos entienden lo mismo por este "nuevo modo" de hacer teología: unos parecen creer que esta teología ha elaborado un método completamente latinoamericano; algunos seguramente la toman de otros autores latinoamericanos sin conocer su proveniencia ulterior; hay quienes piensan que la novedad estriba en el lenguaje o en las categorías de los pueblos originarios; no falta quien no repara en la naturaleza de la cesura respeto de la teología tradicional europea. Se trataría nada menos que, según Leonardo Boff, de un modo distinto de "pensar en teología" (BOFF, L., 1975, p. 129-130). Para su hermano Clodovis Boff lo que estaría en juego, "más que ser un método específico, es un nuevo espíritu teológico, es un nuevo estilo de teologizar" (BOFF, C., 1990, p. 89). Para Noemi se trata fundamentalmente de una teología de la historia (NOEMI, 1998, p. 30-32).

No debiera extrañar, en todo caso, que dada la novedad efectiva de un método que causó perplejidades en los teólogos principales del Concilio la vez que había de usarse en Gaudium et spes (SHICKENDANTZ, 2013, p. 59-63), la noción que se tenga de él a partir de Medellín -que lo toma del Vaticano II-, sea borrosa. A cincuenta años de distancia no se puede

\footnotetext{
${ }^{4}$ Paolo VI, Insegnamenti, Cittá del Vaticano Libreria Editrice Vaticana, p. 657. En su discurso a los obispos latinoamericanos en Roma el 24 de noviembre de 1965, lamenta: "Se diría que la fe del pueblo latinoamericano debe alcanzar todavía su plena madurez de desarrollo".

${ }^{5}$ COSTADOAT, J. El método en la teología de la liberación latinoamericana. Libro en elaboración por el Departamento de Teología de la Universidad Iberoamericana de México.
} 
desconocer que la teología ha hecho avances importantes en la clarificación del método para descifrar los signos de los tiempos (HÜNERMANN, 2014), pero es tal su novedad y tan grandes los cambios que se avizoran con su utilización que aún queda mucho por elaborar.

Los autores, en general, hacen referencia a las palabras de Gustavo Gutiérrez cuando afirma:

"Por todo esto la teología de la liberación nos propone, tal vez, no tanto un nuevo tema para la reflexión, cuanto una nueva manera de hacer teología. La teología como reflexión crítica de la praxis histórica es así una teología liberadora, una teología de la transformación liberadora de la historia de la humanidad y, por ende, también, de la porción de ella - reunida en ecclesiaque confiesa abiertamente a Cristo. Una teología que no se limita a pensar el mundo, sino que busca situarse como un momento del proceso a través del cual el mundo es transformado: abriéndose - en la protesta ante la dignidad humana pisoteada, en la lucha contra el despojo de la inmensa mayoría de los hombres, en el amor que libera, en la construcción de una nueva sociedad, justa y fraternal- al don del reino de Dios" (GUTIÉRREZ, 1990, p. 72).

En estas líneas se hallan las líneas metodológicas principales -aunque no todas- de lo que los autores explicitarán y desarrollarán después:

\section{No se trata fundamentalmente de un nuevo tema}

- La Teología latinoamericana de la liberación no ha querido abocarse a un tema en particular como lo hacen las "teologías de genitivo": la teología del pecado, la revolución, la secularización, la vida religiosa (VARGAS-MACHUCA, 1975, p. 353).

- Esta teología tiene que ver con todos los temas tradicionales de la teología y la fe cristiana en su conjunto, pero los aborda desde la perspectiva de la opresión de los pobres en América Latina (BRIGHENTI, 1994, p. 209).

\section{Teología de la praxis}

- La Teología de la liberación es nueva, además, porque tiene como punto de partida y de término la praxis. En su caso esta praxis consiste en la liberación de los pobres llevada a efecto fundamentalmente por los mismos pobres.

- Por una parte, según Fernando Castillo, la Teología de la liberación debe considerársela como una teología del presente histórico, centrada en el "acontecer histórico concreto en América Latina", sobre los procesos "que estaban viviendo los pueblos latinoamericanos, de las estructuras económicas y sociales que enmarcaban ese presente histórico y de las perspectivas de futuro que se abrían a partir de esos procesos y de las prácticas que los impulsaban" (CASTILLO VELASCO, 1991, p. 141). La realidad histórica en la cual la praxis liberadora tiene lugar requiere ser conocida mediante las ciencias sociales en todos sus aspectos (sociales, 
económicos, políticos y culturales). Solo un conocimiento a fondo de ella hace posible incidir en la misma de un modo transformador.

- Por otra parte, esta praxis debe ser examinada con los ojos de la fe. Es una praxis cristiana. Es seguimiento de Cristo. Equivale a la praxis espiritual que habría tenido Jesús. De un modo sintético Gutiérrez afirma que "el método (el camino) sobre Dios es nuestra espiritualidad" (GUTIÉRREZ, 2013, p. 36).

- La Teología de la liberación arraiga en la realización histórica del reino de Dios. Esto es, en definitiva, lo que ha de discernirse y proseguirse. En palabras de Francisco de Aquino J.: "La realidad que la teología procura inteligir, 'el don del reino de Dios', es una realidad práxico-liberadora: una realidad que se realiza (sin agotarse) en la historia como liberación" (DE AQUINO, 2011, p. 419-420).

- Aun tratándose de una teología de la praxis, la Teología de la liberación depende de las fuentes tradicionales. Es una teología eclesial. Es, según la definición del mismo Gutiérrez una "reflexión crítica sobre la praxis a la luz de la Palabra" (GUTIÉRREZ, 2013, p. 22, 32, 37). La ortopraxis que le interesa propiciar no es ciega, sino que responde a la palabra de Dios conocida en la Iglesia. La diferencia con la teología tradicional es que ella interactúa con las fuentes localizada en el mundo de los pobres. La Teología de la liberación se aboca fundamentalmente a la experiencia histórica de Dios de la Iglesia de los pobres.

\section{Los pobres como manifestación de Dios}

- Aunque la Teología latinoamericana de la liberación se ocupa preferentemente de toda la teología desde la perspectiva de los pobres, sí tiene, además, un tema nuevo: los mismos pobres $\mathrm{y}$, particularmente, su experiencia espiritual de un Dios liberador. Esta constituye una enorme novedad en la historia de la teología. La Teología latinoamericana de la liberación ausculta en los pobres la acción reveladora actual de Dios.

- La mayor de las novedades pareciera consistir en considerar que la historia es un lugar de revelación de Dios y en afirmar que el pobre es un "lugar teológico". La experiencia de Dios en los pobres, según Herrera, no debiera estimarse solo un "simple comienzo, un prólogo del discurso teológico, sino un verdadero 'lugar teológico' que determina una cierta inteligibilidad teológica" (HERRERA, 1975, p. 342). A esto me referiré en adelante.

Agenor Brighenti, sin embargo, ha cuestionado seriamente la pretensión de novedad de la Teología de la liberación. En su tesis doctoral ha podido rastrear con detención el recurso que esta teología ha hecho del método del ver, juzgar y actuar (BRIGHENTI, 1994, p. 207). Para Brighenti "las raíces de la epistemología y del método de la Tdl (Teología de la liberación), oriundas del método de la AC (Acción Católica), que a su vez 
están ligados al método de la TM (teología moderna) y de las TdPs (teologías de lo político), testifican que 'la nueva manera de hacer teología' no es 'comienzo nuevo'" (BRIGHENTI, 1994, p. 253). Los teólogos de la liberación, en realidad, han hecho suya una metodología ya existente. El teólogo brasilero piensa que "reconocer, histórica y epistemológicamente las raíces del método de la TdL (Teología de la liberación), oriundas del método 'ver-juzgar-actuar', un método que el Magisterio tiene notificada su recepción de larga fecha, es hacer justicia a Cardijn y a los militantes de la AC (Acción Católica), especialmente latinoamericanos, los verdaderos pioneros de la Tdl (Teología de la liberación)" (BRIGHENTI, 1994, p. 253).

Así las cosas, cuando se habla de originalidad de la Teología latinoamericana de la liberación habría que decir que lo novedoso ha consistido más bien el uso extraordinario que la Iglesia en América Latina ha hecho del método del que habla Brighenti. Y, sobre todo, lo veremos en adelante, el haber reconocido a los pobres una importancia epistemológica desconocida en la historia de la teología.

\section{Relación de la teología latinoamericana con la modernidad ilustrada}

En la introducción que Virginia Azcuy hace a un libro de Lucio Gera que ella misma edita (AZCUY, 2015, p. 27), reconoce varias "teologías latinoamericanas" entre las cuales las más conocidas son la Teología de la liberación, la Teología argentina del pueblo, la Teología feminista y la Teología indígena, todas en diversas versiones, pero deja abierta la pregunta si acaso pueda hablarse de una pluralidad de "teologías de la liberación", entre las cuales ubicar a la Teología argentina del pueblo. Azcuy advierte que no hay suficiente claridad en el contexto latinoamericano para responder a esta pregunta: la Teología argentina ha sido combatida por sectores teológicos liberacionistas, la Congregación para la Doctrina de la Fe ha cuestionado a la Teología de la liberación y aún no se sabe dónde ubicar, teológicamente hablando, al Papa Francisco. En este punto, Azcuy es cauta respecto del pensamiento de J.C. Scannone, quien resueltamente ubica a la Teología argentina del pueblo como una corriente de la Teología de la liberación (Cf. SCANONNE, 1982, p. 38). Mi opinión es la misma de Scannone. La Teología del pueblo, así como la Teología feminista e indígenas latinoamericanas, han de considerarse teologías modernas de la liberación, pues para ellas el interés por la liberación de sujetos oprimidos colectivos es esencial.

Me detengo a continuación a analizar el pensamiento de dos autores que, desde orillas distintas, toman posición ante el desafío de recurrir a mediaciones teóricas modernas con el objeto de liberar a los pobres en América Latina. 


\subsection{Juan Luis Segundo critica la Teología del pueblo}

Al interior de la Teología de la liberación Juan Luis Segundo distingue "dos tendencias claras" (SEGUNDO, 1984, p. 129). "Si una considera al pueblo como lugar teológico al que tiende como a su objeto, toda la tarea de comprender la fe, la otra considera a ese mismo pueblo como sujeto colectivo de donde parte la correcta interpretación y comprensión de la fe" (SEGUNDO, 1984, p. 129). No es fácil, sin embargo, colocar a los teólogos en una u otra tendencia. El teólogo, como "intelectual orgánico", suele transitar de una a otra. Estos son los casos, según J.L. Segundo, de Leonardo Boff y Jon Sobrino. Sobrino, en particular, se alinea con la segunda ilustración europea, separándose de la primera, considerando a la segunda aún más crítica; pero haciendo así, Sobrino, como un teólogo ilustrado, también se aleja del pueblo como sujeto primero de la teología. “Cómo se puede hacer teología para el pueblo sin tener como sujeto agente al mismo pueblo?" (SEGUNDO, 1984, p. 134). No es un problema fácil de resolver.

Para J.L. Segundo se hace necesario revisar las mediaciones intelectuales implicadas en esta problemática (SEGUNDO, 1984, p. 136). La segunda tendencia no puede fácilmente confiar el conocimiento de la realidad a las ciencias sociales, pues esto significaría renunciar a la mediación filosófica que hace posible concebir al pueblo como sujeto. Se dirá, "las ciencias sociales, con sus análisis sobre los mecanismos de opresión ocultos al propio pueblo, aunque introyectados en él, aparecen más y más como una presunta 'ayuda generosa' ofrecida al pueblo desde fuera de él por gente que pretende hablar en nombre de los 'sin voz'" (SEGUNDO, 1984, p. 138). Así las cosas, la segunda tendencia se aferra a la filosofía para defender al pueblo como sujeto y exigir al teólogo que aprenda del pueblo. Esta sería la postura de E. Dussel y J.C. Scannone. Esta posición ha motivado una nueva valoración de lo autóctono en América Latina, intento que ha ido de la mano de sectores conservadores, apologetas de una visión monolítica del vínculo entre la religión y la cultura del pueblo.

La Iglesia latinoamericana, según J.L. Segundo, se ha visto atravesada por un dilema: ser iglesia de masas, en respeto a la síntesis entre fe y cultura, o ser iglesia de elite, en la cual un conocimiento mayor de Jesús de Nazaret -que, a propósito de lo mismo, habría que ubicar más cerca de la primera tendencia- pudiera forzar al catolicismo latinoamericano a romper su unidad, por de pronto, primitiva. En las sociedades modernas es posible reconocer ámbitos que pueden integrar cada cual, por su parte, elementos nuevos. En cambio, en las culturas más primitivas sus diversos elementos están estrecha e inseparablemente vinculados unos a otros. En este escenario, habrá que contar con que una religiosidad popular, íntimamente dependiente de una cultura popular bastante impermeable a los esfuerzos evangelizadores de la Iglesia institucional, normalmente se cerrará a lo que las pretensiones de ilustración quieran hacer con ella. En suma, en la Iglesia latinoamericana, hay quienes piensan que una nueva 
comprensión y aceptación del mensaje cristiano requiere integrar la secularización y otros que estiman que la sólida e inmensamente mayoritaria religión popular debiera reforzar la cultura del pueblo. J.L. Segundo opta por una Iglesia "mucho menos numerosa", fruto de "una nueva y madura evangelización" (SEGUNDO, 1984, p. 158).

Juan Carlos Scannone introduce una distinción similar a la de J.L. Segundo (SCANNONE, 1975, p. 353) . Pero se ubica en la orilla opuesta a este. Privilegia la importancia de considerar al pueblo latinoamericano como el primer oprimido y primer sujeto de la teología (SCANNONE, 1975, p. 362 , 170). El teólogo debe acompañar al pueblo en el camino que autónomamente debe hacer. No me detendré, sin embargo, en Scannone, sino en Pedro Trigo. Trigo ha cumplido como pocos teólogos latinoamericanos la tarea que Scannone señala a la teología, toda vez que la suya ha sido elaborada con las mismas comunidades populares.

\subsection{Pedro Trigo exige al teólogo iniciarse en el mundo y la religión popular}

Pedro Trigo reacciona vigorosamente en contra de sus compañeros de camino que han hecho del socialismo el medio de la liberación. Él piensa que el horizonte revolucionario y socialista fue asumido por los teólogos de la liberación a un alto precio. Trigo centra su mirada en el teólogo. Este, en América Latina, ha debido cumplir la función de retraducir al nivel religioso cristiano los conceptos del imaginario de izquierda y, además, justificar ante la izquierda y ante los demás cristianos la convergencia con el socialismo no obstante las incongruencias de fondo. Así las cosas, "si el mundo-de-vida era las izquierdas, el papel de lo teológico era fundamentalmente ideológico" (TRIGO, 2001, p. 111). "Dicho de otra manera, si la teología es acto segundo y la praxis de liberación el acto primero, desde esta perspectiva esa praxis era simplemente la de la izquierda y en concreto el teólogo participaba en ella en la elaboración teórica, en los análisis de coyuntura, en la discusión de bases programáticas, en la propaganda y defensa de este horizonte, y eventualmente como extensionista y en tareas organizativas y de apoyo" (TRIGO, 2001, p. 112).

De aquí que Trigo exija al teólogo adoptar, antes que nada, el mundo-de-vida de los pobres, a efecto de lo cual este debe renunciar por completo a la "relación ilustrada" con el mundo popular. Sostiene: "Mi propuesta es que la Teología de la liberación comienza cuando acaba la relación ilustrada. En este sentido, la condición de intelectual de la Ilustración

\footnotetext{
${ }^{6}$ Distingue entre dos líneas-fuerza: "una de esas líneas tendió -en el post-Medellín- a ir adoptando cada vez más conscientemente las categorías o el método marxistas de análisis y transformación de la realidad, dentro del discurso teológico. Otra de esas líneas se dirigió más bien a la asunción, por la teología, de la cultura y religiosidad populares latinoamericanas".
} 
liberal y la de intelectual de la Ilustración socialista serían igualmente heterogéneas respecto de la Teología de la liberación" (TRIGO, 2001, p. 113). Trigo se aleja, en este sentido, de J.L. Segundo, así como del Jon Sobrino que rescata la segunda Ilustración.

Trigo delinea un arduo itinerario que el teólogo debiera recorrer para hacerse cristiano y, por esta vía, adquirir la condición de posibilidad fundamental para llegar a ser teólogo de la liberación. A saber, el teólogo tendría que "volver a nacer", tendría que entrar en "un proceso de iniciación", para llegar a "superar la relación ilustrada". Esto, sin embargo, es imposible. El ilustrado es por excelencia alguien que "se conoce a sí mismo y se posee a sí mismo, es el que se autolibera por el uso soberano de su razón y de sus facultades, el que tiene en sí su principio y fundamento, el autárquico" (TRIGO, 2001, p. 115). La iniciación requerida solo puede tener lugar a través de la experiencia de un "límite infranqueable", equivalente a hacer "la experiencia del mal en uno, por el convencimiento de la imposibilidad de alcanzar la salvación por las propias fuerzas por la apertura a aquello que va a poner a valer al sujeto" (TRIGO, 2001, p. 115).

Esta iniciación ha de consistir fundamentalmente en una experiencia de Dios trino en medio de la cultura popular. El teólogo debiera hacer suya la figura del Siervo: "un pobre de espíritu, pobre también con espíritu y amigos de pobres y el que se solidariza al modo de Jesús: asumiendo los problemas, cargando con las dolencias y sanando así los ambientes y curando las enfermedades del cuerpo y el corazón, él, pecador y enfermo siempre, sanado y perdonado cada día por Jesús" (TRIGO, 2001, p. 119). No otra debiera ser su praxis, pues es este el corazón de la praxis auténticamente liberadora, el acto primero del cual la Teología de la liberación pretende ser el acto segundo (TRIGO, 2001, p. 118). Esta praxis debiera radicar en la praxis liberadora de Jesús, por lo cual no puede esperarse que la praxis política, esencialmente coactiva, pueda ser liberadora. Trigo, sin embargo, pide no demonizar la política.

Esta iniciación, según Trigo, ha de tener lugar en las comunidades eclesiales de base. En ellas es posible superar la "relación ilustrada". En ellas el "teólogo se va haciendo cristiano junto con el pueblo creyente y oprimido" (TRIGO, 2001, p. 122). No debe mimetizarse con el pueblo. La relación ha de transformarlos a ambos. "Un síntoma decisivo de que la relación se mantiene como horizontal (en cuanto cristianos) es que se dé en la casa del pueblo, en sus casas físicas desde luego, pero también en la cultura popular (en su lenguaje, en sus ritmos, en sus tópicos, en su lógica, en sus sentires, en sus expresiones simbólicas, en su modo de organizarse...) y sobre todo, en el catolicismo popular" (TRIGO, 2001, p. 123-124). Continúa: "Si la comunidad tiene que mantenerse como de base (si no, no es comunidad sino grupo y no de base ya que en él hay relaciones piramidales), esa casa no puede ser otra que la cultura y religión populares" (TRIGO, 2001, p. 124). 
El teólogo recibe en esta relación la fe del pueblo. Pero también tiene algo que dar. Por de pronto, su propia persona, y también su fe, en vez de su "proyecto". El teólogo da, además, como teólogo. Él hace un aporte específico. Su misión es, principalmente, conectar a la comunidad con la Tradición. Tiene que ayudar a que la palabra de Dios sea escuchada. Es así como Trigo entiende que ha de ser aquel "otro modo de hacer teología", pues esta no tiene tanto que ver con los resultados como con "el modo de producción" (TRIGO, 2001, p. 132-133).

Hasta aquí podemos decir que la relación de la Teología de la liberación con la necesidad de ilustrar al pueblo pobre latinoamericano es compleja. Si los teólogos como "intelectuales orgánicos" pretenden conducir al pueblo cristiano a su liberación con los instrumentos analíticos de las ciencias modernas, pero sin contar con este pueblo como sujeto de su propia liberación, nada más profundizarán, bajo otro respecto, la alienación en que vive. A mi parecer la otra posibilidad también es problemática. Si los teólogos se limitan a elevar a concepto la experiencia colectiva de Dios del pueblo, con especial respeto de la cultura y religión popular, contribuirán muy poco a sacarlo de la postración social e inveterada en que se encuentra y a purificar los aspectos alienantes de su religiosidad. Podrán, en cambio, mistificar un modo de ser latinoamericano impermeable a la dimensión histórica de la realidad en la cual los pueblos crecen en humanidad.

Juan Luis Segundo acierta al explicar ambas tendencias de la Teología de la liberación. Muestra el problema. Pero no queda claro en su planteamiento si es posible o no una comunicabilidad entre la Ilustración y la cultura popular latinoamericana como para que, eventualmente, pudiera un pobre asumir los instrumentos liberadores de la modernidad sin dejar de ser latinoamericano. No basta con que afirme que normalmente las tendencias que distingue se den "mixtas" (COSTADOAT, 2015, 2017) 7 .

Pedro Trigo, por su parte, deja muy claro que el sujeto ulterior de la Teología de la liberación es el pobre cultural y religiosamente considerado, pero el sujeto "con espíritu", el pobre que vive espiritualmente su vida y no un pobre cualquiera. Supera así la "relación ilustrada" a la que J.L. Segundo jamás renunciaría. Sin embargo, al desconfiar tan radicalmente de los esfuerzos socialistas por conducir al pueblo a su liberación, no queda claro en su pensamiento que, más que desistir de la política, reniega de sus sacralización. La política, según Trigo, genera relaciones jerárquicas coercitivas. El problema, si fuera el caso, sería dejar al teólogo en la situación de acompañar a un pueblo en el curso de un camino que puede seguir una dirección cualquiera.

\footnotetext{
${ }^{7}$ En dos estudios de caso he podido investigar la relación que se ha dado en dos personas del mundo popular entre su cristianismo tradicional y la evangelización ilustrada post-conciliar. Mi conclusión ha sido, en ambos casos, que la compenetración entre ambos cristianismos es posible y feliz, e incluso, en uno de ellos, que es posible la integración entre un catolicismo muy tradicional y una praxis de compromiso político muy de izquierda.
} 
Esta posición de Trigo es discutible. En cuanto a lo que en este tema más interesa, sin embargo, el teólogo caraqueño acierta en lo fundamental. No puede haber Teología de la liberación alguna que no sea teología sobre la experiencia de Dios; sobre la praxis de seguimiento de Cristo, geográfica y temporalmente determinada en el mundo y la Iglesia de los pobres pues, en sentido estricto, solo Dios es liberador.

\section{Status Quaestionis de la Teología de la Liberación}

A modo de status quaestionis podría ofrecerse un mapa de las diversas versiones de la Teología de la liberación y, al interior de cada una de ellas, mostrar el desarrollo de los principales temas. Al terminar este artículo, en cambio, solo quiero decir una palabra acerca del método. Me refiero a solamente a un punto, pero uno a partir de lo cual la Teología de la liberación tendría que hacer un avance decisivo.

\section{1 ¿Qué es la praxis desde un punto de vista teológico?}

Desde sus orígenes la Teología de la liberación ha querido ser una reflexión crítica de la praxis. Esta, como acto primero respecto del cual la teología es el acto segundo, ha sido identificada con un compromiso político liberador, con luchas liberadoras varias, con el modo cultural y religioso que tiene un pueblo para resistir en un mundo adverso, con el seguimiento de Cristo o con el advenimiento del reino ya en esta historia. Estos aspectos, a mi juicio, no son excluyentes. Todos ellos enriquecen el concepto.

Dos son los teólogos que en el último tiempo han hecho un aporte importante en la compresión de la praxis, Pedro Trigo y Francisco de Aquino. Trigo subraya la dimensión pneumatológica de la praxis de la Teología de la liberación. Por una parte, hemos visto, deplora la praxis de los cristianos cuando ha sido cooptada por la praxis de las izquierdas. Por otra parte, no acepta que la teología deba reflexionar principalmente sobre la fe objetiva de la Iglesia (fides quae). Antes bien, la teología, según Trigo, debe enfocarse en la praxis espiritual de los cristianos. La teología ha de ser actual "porque el misterio cristiano se revela en concreto como salvación para esta época, y para que se revele realmente hoy lo que sucedió una vez en la historia, tiene que ser contado hoy como buena nueva para nosotros y tiene que ser aceptado hoy" (TRIGO, 2010, p. 160). El supuesto fundamental de la teología así concebida es que "el Espíritu es la actualidad de Dios" (TRIGO, 2010, p. 169) y a ella no le cabe otra cosa que abocarse a lo que el Espíritu obra a través de una praxis de seguimiento de Cristo equivalente, no igual, a la que Jesús tuvo en su época (TRIGO, 2010, p. 220).

Tan importante es la praxis para la teología que sus mismos criterios son pragmáticos (TRIGO, 2010, p. 144). La teología es "interesada". El teólogo 
no puede ser neutral. Por el contrario, ha de tomar partido en las luchas de su época. Lo que impide ser en esto ideológico, es que su teología debe ser también eclesial. Su tarea consiste principalmente en actualizar la "tradición constituyente", a saber, "lo que se ha creído siempre, por todas las Iglesias y por todos los fieles, y también lo que, habiéndose clarificado en una época, ha sido asumido en adelante por toda la Iglesia como un sentir católico" (TRIGO, 2010, p. 220), de un modo creativo.

F. de Aquino piensa similar a Trigo. De Aquino aprovecha un concepto secular de praxis para afirmar que la praxis cristiana es "un momento constitutivo y determinante del conocimiento teológico en cuanto tal" (AQUINO, 2010, p. 477). Según él, entre la teoría y la praxis ha de reconocerse una relación de respectividad (AQUINO, 2010, p. 481) que hace posible superar el dualismo de dos historias paralelas, la profana y la sagrada (AQUINO, 2010, p. 486). Para F. de Aquino -bajo el influjo de I. Ellacuría- la teología tiene un carácter práxico:

"El carácter práxico de la teología se refiere antes de todo a la propia realidad a ser inteligida por ella. Diferente de lo que se suele pensar y de lo que da a entender una mirada meramente etimológica de la palabra (Theos = Dios y logia = palabra), la teología no trata de Dios sin más. Trata de Dios, sí, en cuanto y en la medida en que se hace presente y actúa en la historia. Trata, por tanto, de la acción de Dios en la historia que es siempre, de alguna forma y en alguna medida, re-acción ante determinadas situaciones y acontecimientos (salvación) e inter-acción con personas y pueblos concretos (Pueblo de Dios - Iglesia)" (AQUINO, 2010, p. 490).

La praxis histórica de los cristianos, según de Aquino, es el objeto primero de la teología. A esta praxis le es inherente una teología y, esta misma, es una suerte de praxis. Ella es, de suyo, histórica. "Depende, en gran parte, de las posibilidades intelectivas disponibles en un determinado momento, de su apropiación y, a partir de ella, de la creación de nuevas posibilidades intelectivas". Puede incluso darse que en un determinado momento no existan las mejores "posibilidades teóricas" (AQUINO, 2010, p. 493). Aun así, habrá de escogerse la que mejor responda a los "intereses" práxicos en juego (AQUINO, 2010, p. 494-495). Estos intereses, por una parte: "condiciona(n) y determina(n) de alguna manera el propio proceso de intelección" (AQUINO, 2010, p. 496) y, por otra, demandan de la teología una comprobación en la realidad histórica del reino al que ella se debe. La praxis, "además de lugar de experiencia o comprobación de la teoría (dónde), se constituye en principio con el cual se mide o se pondera su veracidad (cómo). Si es teoría de una praxis, la teología puede y debe ser comprobada en esa praxis (lugar) y puede y debe ser practicable-historizable (principio)" (AQUINO, 2010, p. 496).

\section{2 ¿Son los pobres "lugar teológico" de conocimiento de Dios?}

Llegamos aquí a un punto de quiebre. Si la praxis cristiana constituye una fuente de conocimiento teológico (de Aquino), si el foco principal de 
atención de la teología es la actualidad de la manifestación de Dios (Trigo), ¿es la solidaridad con los pobres o la praxis de liberación de los mismos pobres un "lugar teológico" que ha de entrar en juego hermenéutico con los demás lugares teológicos? Bien parece que la novedad última de la Teología de la liberación, y la identificación de esta con la Teología latinoamericana, se juega en la respuesta a esta pregunta.

En una investigación anterior he constatado que el uso de la terminología de los "lugares teológicos" es errática entre los teólogos latinoamericanos (COSTADOAT, 2017, 2018, 2017b) ${ }^{8}$. Unos refieren a la obra de Melchor Cano, sin los cuidados suficientes. Otros no parecen sentirse obligados a usar la nomenclatura de Cano, pero al utilizar la expresión "lugar teológico" no aclaran en qué consiste la red epistemológica en la cual la historia ha de considerarse un lugar teológico.

En esta materia hay que distinguir entre los teólogos que usan la expresión "lugar teológico" como sinónimo de lugar hermenéutico y quienes, yendo más lejos, sostienen que un determinado lugar hermenéutico -lugar social, cultural, religioso- puede también constituir, en términos de Cano, un "lugar teológico propio", es decir, una fuente de revelación de Dios. Pues no es lo mismo que "desde" un lugar histórico, como podría ser el "mundo de los pobres", se comprenda mejor la palabra de Dios, a que "en" ese mismo lugar pueda oírse la palabra actual de Dios.

Pues bien, Ignacio Ellacuría debe ser ubicado entre los autores que sostienen que los pobres son "lugar teológico", pero a modo de "lugar hermenéutico". A primera vista pudiera pensarse que para Ellacuría los pobres "revelan" a Dios sin más. Afirma el mártir de la UCA: "Los pobres en América Latina son 'lugar teológico' en cuanto constituyen la máxima y escandalosa presencia profética y apocalíptica del Dios cristiano y, consiguientemente, el lugar privilegiado de la praxis y de la reflexión cristiana" (ELLACURÍA, 1981, p. 231). Para Ellacuría los pobres hacen visible a Jesús en la historia por lo cual son un "especial lugar teológico" (ELLACURÍA, 1981, p. 232). Pero cuando el teólogo pone a los pobres en relación con las fuentes tradicionales de la teología, resulta otra cosa:

“...es conveniente distinguir, al menos metodológicamente, "lugar" y "fuen-

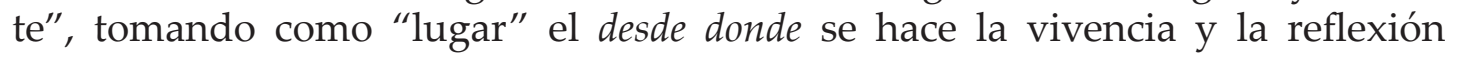
teológicas, y tomando como "fuente" o depósito aquello que de una u otra forma mantiene los contenidos de la fe. La distinción no es estricta, ni menos excluyente, porque de algún modo el lugar es fuente, en cuanto aquél hace que ésta dé de sí esto o lo otro, de modo que gracias al lugar y en virtud de él se actualizan y se hacen realmente presentes unos determinados contenidos" (ELLACURÍA, 1981, p. 234).

\footnotetext{
${ }^{8}$ Jorge Costadoat, "Dios habla hoy. En busca de un nuevo concepto de revelación", será publicado en Franciscanum, 169 enero-junio 2018.
} 
En Ellacuría, en suma, los pobres tienen una enorme importancia porque la comprensión de las fuentes, desde ellos, hace que estas "dé(n) de sí esto o lo otro". No es lo mismo leerlas en cualquier lugar. Pero, en sentido estricto, Ellacuría se restringe a la importancia que ha de concederse a los pobres como punto de arranque en el círculo hermenéutico.

Otros teólogos de la liberación llegan a afirmar algo parecido. Es común la convicción acerca de la historicidad de la revelación, por lo que resulta corriente hablar de la historia y de los pobres como de "lugar teológico". En muy pocos, en cambio, hay viva conciencia de la diferencia señalada. Llama poderosamente la atención, en todo caso, que Clodovis Boff, el autor que más se ha ocupado del método de la Teología de la liberación, haya terminado por negar tajantemente que los pobres tengan un valor sacramental. A lo más les concede ser un "lugar teológico ajeno" (BOFF, C., 2009, p. 902, 903).

En esta materia ninguno de los teólogos latinoamericanos va más lejos que Jesús Herrera Aceves al bosquejar el método de la Teología de la liberación. Según Herrera, la novedad del método de la Teología de la liberación consiste en ser una "reflexión teológica (que) parte del análisis de la realidad situacional concreta latinoamericana...", no como "un conocimiento puramente teórico de la situación, sino (como) una situación compartida, vivida, experimentada en el compromiso cristiano con los pobres" (HERRERA, 1975, p. 341-342); como "un verdadero «lugar teológico» que determina una cierta inteligibilidad teológica" (HERRERA, 1975, p. 342). Herrera procura aclarar y precisar cómo la historia, los acontecimientos, son un "lugar teológico" y de qué forma lo son con relación a la "fuente privilegiada de la teología" (HERRERA, 1975, p. 343) que es la palabra de Dios. El jesuita mexicano parte considerando que la encarnación constituye el lugar teológico por excelencia. ¿Cómo se relaciona este acontecimiento con los demás acontecimientos de una historia que se proyecta al esjaton salvífico?

Herrera, a este efecto, bosqueja un programa metodológico integral. El jesuita mexicano distingue cuatro modos de relacionar los acontecimientos históricos con la palabra de Dios. El primero, el más importante, entiende que "los acontecimientos son palabra de Dios, pues Dios nos habla a través de ellos". Ellos "son" "palabras de Dios" (relación de "identidad"), "sea porque constituyen la Palabra de Dios" (a modo de aquella revelación que "se conserva en la Iglesia como memoria Christi"), sea porque "constituyen la Palabra de Dios (en sentido "derivado"), descubierta por la Iglesia como signo de los tiempos" (HERRERA, 1975, p. 346). ${ }^{9}$

Para que esta primera distinción entre en juego se requiere, en segundo lugar, entender la historia actual "a la luz de la palabra" (HERRERA, 1975,

\footnotetext{
${ }^{9}$ Las cursivas son mías.
} 
p. 347); en tercer lugar, comprender la palabra "a la luz del presente" (HERRERA, 1975, p. 348); y cuarto, recurrir al auxilio de las ciencias del hombre (la racionalidad científica). Herrera concluye:

“Estos cuatro tipos de relación de los acontecimientos con la Palabra de Dios nos muestran en general de qué modos puede ser utilizada la historia como «lugar teológico». Objetivamente hablando los acontecimientos son en sí mismos, y en su racionalidad científica capaces de ser un «lugar teológico» polivalente. Pero en realidad no empiezan a funcionar como «lugar teológico» sino cuando los creyentes asumen esa historia, esos acontecimientos en su experiencia eclesial originada en la fe, cuando los creyentes encarnan su fe en el contexto histórico y cultural en que viven" (HERRERA, 1975, p. 349).

Herrera se extiende luego en la explicación de esto último, a saber, en la necesidad de considerar la tradición de la Iglesia para discernir en la historia la palabra de Dios. Cuesta entender que los teólogos de la liberación no hayan tomado en cuenta la importancia del artículo de Herrera en comento, escrito hace ya más de cuarenta años.

\section{Conclusiones}

1 - La presente investigación ha sido hecha con el propósito de identificar la Teología latinoamericana con la Teología de la liberación. Espero haber ofrecido suficientes argumentos para concluir que ambas no debieran ser consideradas sino dos aspectos de una misma teología. Hay auténtica Teología latinoamericana cuando esta promueve la liberación de sujetos oprimidos y hay verdadera Teología de la liberación allí donde la teología tiene en cuenta la participación protagónica de los sujetos latinoamericanos en su propia liberación y reflexión teológica. La Iglesia que arraiga en América Latina, desde Medellín en adelante, al procurar discernir sus propios signos de los tiempos, ha conjugado estos dos aspectos impulsando una praxis liberadora de los latinoamericanos en cuanto tales.

En algún momento pudo distinguirse entre una Teología latinoamericana antes y después del Concilio. En base a lo dicho anteriormente, en sentido estricto, no debiera llamarse "latinoamericana" la teología europea al servicio de la formación del clero nativo en América Latina. La teología anterior al Concilio, aún enseñada en la mayoría de los centros teológicos del continente, debe considerarse alienante, pues en la medida que ha regido a la Iglesia latinoamericana ha impedido su surgimiento como iglesia regional autóctona.

Solo después del Vaticano II ha podido constatarse un camino de superación de la dependencia intelectual de la Iglesia latinoamericana respecto de la teología europea. Esta constatación, corriente en los años sesenta, fue vivida como un acceso a la "mayoría de edad", como un saberse en 
camino a la adultez. El desarrollo de una Teología de la liberación que respondiera a la situación de opresión, teología por cierto ilustrada, incoaba sin embargo la emergencia de sujetos latinoamericanos adultos y teólogos de su praxis histórica.

2 - La teología que en América Latina se llamó a sí misma Teología de la liberación, quiso ser "un nuevo modo" de hacer teología. Con esta expresión se pretendía marcar una diferencia respecto la teología que hasta entonces había primado en el continente. Sin embargo, miradas las cosas de cerca, si se trata de reconocer alguna novedad, es necesario hacer distinciones. La Teología de la liberación adoptó el método teológico de Gaudium et spes de atender a los signos de los tiempos y el método de la Acción Católica del ver, juzgar y actuar, método europeo usado ya en Latinoamérica desde hacía años. La novedad solo ha podido consistir en el amplio uso que la Iglesia Latinoamericana hizo de estos métodos inductivos para comprender su misión histórica y adoptar las modalidades que esta misión le imponía. No parece que haya habido alguna otra Iglesia en la cual el método de Gaudium et spes haya tenido más impacto. Sin embargo, la originalidad mayor, y completa, de la Teología latinoamericana de la liberación ha sido constatar que Dios "opta por los pobres". Por cierto, el método teológico del ver, juzgar y actuar, y la praxis liberadora y teológica correspondiente, han ayudado a llegar a esta conclusión. Pero, independientemente de esto, el más importante descubrimiento de esta teología es que el pobre, mediante su praxis de liberación o a través del mero hecho de ser víctima inocente, "revela" a Dios en el presente. Él, como sujeto latinoamericano y objeto de su liberación, y en cuanto cristiano integrante de una tradición eclesial, adquiere una autoridad que el resto de la Iglesia debe reconocer.

3 - El status quaestionis de la Teología latinoamericana de la liberación tiene que ver con este punto de llegada y la necesidad, precisamente, de relacionar ambas palabras de Dios, la que proviene de la Escritura y la que se expresa en la historia, la de ayer y la de hoy, especialmente a través de las bocas de los pobres. ¿Cuál es el método que se hace cargo de este enorme desafío? Estamos en los comienzos de su desarrollo. Lo que está en juego es extraordinariamente novedoso en la historia de la teología.

En este avance de la Teología latinoamericana de la liberación hacia su concepto, es posible reconocer tres asuntos especialmente relevantes. Primero, que ha solido hablarse de la historia o de los pobres como de "lugar teológico" sin suficiente cuidado terminológico. Unos autores han usado esta denominación para designar una revelación o palabra actual de Dios. Otros, en cambio, han utilizado la expresión para referirse al "desde" contextual, al "lugar hermenéutico", que permite comprender la Escritura. Los primeros descubren en el "lugar hermenéutico" lo que según la nomenclatura de M. Cano correspondería a un "lugar teológico propio". Los segundos no llegan tan lejos o, aun cuando quisieran afirmar algo así, sus explicaciones se restringieran al círculo hermenéutico. 
Un segundo asunto importante tiene que ver particularmente con el teólogo como "intelectual orgánico". ¿Debe el teólogo conducir al pueblo creyente a liberación de las condiciones estructurales y políticas que lo mantienen en la pobreza? ¿O más bien debiera iniciarse en el cristianismo de los pobres y acompañarlos en las comunidades populares, ayudándolas a mediar su praxis cristiana con la tradición de la Iglesia, no importando a dónde los lleve el proceso? Ni J.L. Segundo ni P. Trigo abordan a fondo la posibilidad de una compenetración de ambos trayectos.

El tercer asunto dice relación con la praxis en sentido estricto. La teología en América Latina ha ido tomando viva conciencia de que la praxis a que se debe -sea personal, eclesial o política-, ha de ser siempre una praxis espiritual, pues es en este tipo de praxis donde se discierne la actividad del Espíritu que es el objeto último de la teología. De un modo semejante a como el momento del "ver" del método señalado atañe a la observación de la acción de Dios en la historia, la cual requiere del recurso a las ciencias sociales para afinar el diagnóstico, es en el seguimiento de Cristo donde se observa, en definitiva, esta acción. No corresponde que la teología venga a avalar sin más la praxis de las izquierdas. La praxis cristiana es auténtica praxis de liberación -en todos los planos en la cual esta es posible- cuando ella es obra del Espíritu y, por esto, ella es la fuente de conocimiento teológico por excelencia. De aquí que el teólogo de la liberación es tal cuando toma partido por los pobres y cuando interactúa con compresión teológica que los mismos pobres tienen de su vida.

\section{Referencias}

AZCUY, V. Introducción. En: GERA, L. La teología argentina del pueblo. Santiago: Pontificia Universidad Católica de Chile, Universidad Alberto Hurtado, 2015.

BEOZZO, J. O.; HÜNERMANN, P.: SCHICKENDANTZ, C. F. Nuevas pobrezas e identidades emergentes: signos de los tiempos en América Latina. Córdoba: Editorial de la Universidad Católica de Córdoba, 2006.

BOFF, C. Epistemología y método de la teología de la liberación. En: ELLACURÍA, I.; SOBRINO, J. Mysterium liberationis: conceptos fundamentales de la teología de la liberación. Madrid: Trotta, 1990. Tomo I, p. 79-111.

BOFF, C. Volta ao fundamento: réplica. Revista Eclesiástica Brasileira, Petrópolis, v. 272, p. 892-927, 2008.

BOFF, L. ¿Qué es hacer teología desde América Latina?, En: DUSSEL, E., RUIZ MALDONADO, E. Liberación y cautiverio: debates en torno al método de la teología en América Latina. México D.F.: El Encuentro, 1975. p. 129-154.

BRIGHENTI, A. Raíces de la epistemología y del método de la teología latinoamericana. Medellín, v. XX, n.78, p. 207-254, 1994.

CASTILLO, F. Teología y liberación en los noventa. Un análisis de la coyuntura latinoamericana. Tópicos, v. 3, n. 90, p. 145-172, 1991. 
CASTILLO, F.; NOEMI, J.; ARTEAGA, J.; RODRÍGUEZ, J. Teoría y praxis en la Teología de la liberación. Teología y Vida, Chile, n. 1, p. 3-38, 1974.

CODINA, V. ¿Qué es la Teología de la liberación?. Santiago: Rehue, 1987.

COSTADOAT, J. Cristología latinoamericana: Bibliografía (1968-2000). Teología y vida, Chile, v. XLV, n.1, p. 18-61, 2004.

. La imagen de Cristo de Edith Cabezas. Teología y vida, Chile, v. LVI, n. 4, p. 407-429, 2015.

- ¿Hacia un nuevo concepto de revelación? La historia como lugar teológico en la Teología de la liberación. En: Lugares e interpelaciones de Dios: discernir los signos de los tiempos. Santiago: Editorial Universidad Alberto Hurtado, 2017. p. 105-32.

. Novedad de la Teología de la liberación en la concepción de la revelación. Revista Teología, t. LIV, n. 124, p. 27-45, 2017.

El cristianismo de Hilda Moreno: un estudio de caso. Cuadernos de teología, Buenos Aires, v. IX, n. 1, p. 126-154, 2017.

Dios habla hoy: en busca de un nuevo concepto de revelación (por publicar). Franciscanum, Bogotá, n. 169, enero /jun. 2018.

. El método en la teología de la liberación latinoamericana. En: Libro en elaboración, Departamento de Teología de la Universidad Iberoamericana de México.

AQUINO JUNIOR, F. El carácter práxico de la teología: un enfoque epistemológico: Teología y vida, Chile, v. LI, n. 4, p.477-499, 2010.

. Atualidade da teología da libertação. Theologica Xaveriana, Bogotá, n.172, p. 397-422, 2011.

DUSSEL, E. Teología de la liberación. México: Potrerillos editores, 1995.

ELLACURÍA, I. Los pobres, lugar teológico en América Latina. Misión abierta, n. 4-5, p. 225-240, 1981.

GUTIÉRREZ, G. Teología de la liberación: perspectivas. Salamanca: Sígueme, 1972.

. La fuerza histórica de los pobres. Salamanca: Sígueme, 1982.

. Vaticano II y la Iglesia latinoamericana. Fe y solidaridad, n. 55, p. 2-18, 1985.

La teología latinoamericana y caribeña: trayectoria y perspectivas. Congreso Continental de Teología 2012 v. 38, p. 14-29. Disponible en: http://www.seleccionesdeteologia.net/selecciones/1lib/vol53/211/211_Gutierrez.pdf. Acceso en: 07 marzo 2018.

HERRERA ACEVES, J., La historia, lugar teológico dentro de la experiencia eclesial. En: DUSSEL, E., RUIZ MALDONADO, E. Liberación y cautiverio: debates en torno al método de la teología en América Latina. México D.F: El Encuentro, 1975. p. 341-352.

MC GRATH, M. La misión de la teología en Latinoamérica. Anales de la Facultad de Teología, v. XII, p. 13-24, 1960.

NOEMI, J. Teología latinoamericana: rasgos, imperativos y desafío. Santiago: Centro Ecuménico Diego de Medellín, 1998.

HÜNNERMAN, P. El Concilio Vaticano II como software de la Iglesia actual. Santiago: Universidad Alberto Hurtado, 2014. 
PAOLO VI. Insegnamenti di Paolo VI. Cittá del Vaticano: Libreria Editrice Vaticana, 1964. p. 657.

SCANNONE, J. C. Teología, cultura popular y discernimiento: hacia una teología que acompañe a los pueblos latinoamericanos en su proceso de liberación. En: ARDILES, O.; et al. Cultura popular y filosofía de la liberación: una perspectiva latinoamericana. Buenos Aires: Fernando García Campeiro, 1975. p. 351-376.

. La teología de la liberación. Caracterización, corrientes, etapas. Stromata, Buenos Aires, n. 38, p. 3-40, 1982.

. El método de la teología de la liberación. Theologica Xaveriana, Bogotá, n. 34, p. 369-399, 1984.

SCHICKENTANTZ, C. F. Un elipse con dos focos. Hacia un nuevo método teológico a partir de Gaudium et spes. En: Teología de los signos de los tiempos latinoamericanos: horizontes, criterios y métodos. Santiago: Universidad Alberto Hurtado, Centro Teológico Manuel Larraín, 2013. p. 53-87.

SEGUNDO, J. L. Dos teologías de la liberación. En: Teología abierta. Madrid: Cristiandad, 1984. v. III, p. 129-159..

SOBRINO, J. La resurrección de la verdadera Iglesia: los pobres, lugar teológico de la eclesiología. Santander: Sal Terrae, 1981.

Trotta, 1991.

. Jesucristo liberador: lectura histórico-teológica de Jesús de Nazaret. Madrid:

. El principio misericordia. Santander: Sal Terrae, 1992.

TRIGO, P. El método en teología, en XXX años de itinerancia. Iter, Caracas, p. 135-230, 2010.

. Cuál es el acto primero del que la Teología de la liberación es acto segundo. Iter, Caracas, n. 25, p. 109-36, 2001.

VARGAS-MACHUCA, A. Teología y mundo contemporáneo: homenaje a K. Rahner en su 70 cumpleaños. Madrid: Cristiandad, 1975.

Artículo sometido en 03.03.2018 y aprobado en 03.04.2018.

Jorge Costadoat, SJ es Doctor en Teología por la Pontificia Universidad Gregoriana, Roma (1993). Profesor en lo Centro Teológico Manuel Larraín, Facultad de Teología de la Pontificia Universidad Católica de Chile. Publicaciones en Academia.edu. Orcid.org/0000-0002-33649899. jcostado@uc.cl

Dirección: Casilla 597

Santiago - Chile 